\title{
Socioeconomic inequality in noncommunicable diseases: Results from a baseline Persian cohort study
}

\author{
Mehdi Sharafi ${ }^{1}$, Ehsan Bahramali ${ }^{2}$, Mojtaba Farjam $^{2}$, Shahab Rezaeian ${ }^{3,4}$, Sima Afrashteh ${ }^{1}$, Zahra Amiri ${ }^{5^{*}}$ (D) \\ Received: 11 Dec 2019 \\ Published: 16 Jun 2021
}

\begin{abstract}
Background: Contrary to health indices advancement during recent years, health inequalities are still a global challenge. This study aimed to determine socioeconomic factors for noncommunicable diseases using concentration indices (CI).

Methods: This cross-sectional study was conducted on the baseline data from a cohort study in Fasa (southern Iran). Principle component analysis was used to measure asset index. Moreover, socioeconomic inequalities were calculated by CI. Analysis was done at $95 \%$ confidence level using STATA software.

Results: A total of 7990 individuals were included in the study. The highest negative CIs were significantly found for epilepsy (-0.334), paramnesia $(-0.255)$, and learning disabilities $(-0.063)$, respectively, and the lowest were significantly found for chronic headaches $(-0.046)$, recurrent headaches $(-0.03)$, infertility $(-0.028)$ and hypertension $(-0.057)$. This index was positive for breast cancer (0.298). Furthermore, it was not Significant for diabetes, thyroid disorders, depression, and chronic lung diseases.

Conclusion: The findings showed a significant inequality in the most of the noncommunicable diseases in the region, which are more concentrated among the poorest population. Policymakers in the health system and city planners should consider these results to decrease the burden of noncommunicable diseases in the society by identifying vulnerable subcategories.
\end{abstract}

Keywords: Inequality, Noncommunicable Diseases, Concentration Index

Conflicts of Interest: None declared

Funding: Fasa University of Medical Sciences(IR.FUMS.REC.1397.061)

\section{*This work has been published under CC BY-NC-SA 1.0 license. \\ Copyright $\odot$ Iran University of Medical Sciences}

Cite this article as: Sharafi M, Bahramali E, Farjam M, Rezaeian Sh, Afrashteh S, Amiri Z. Socioeconomic inequality in noncommunicable diseases: Results from a baseline Persian cohort study. Med J Islam Repub Iran. 2021 (16 Jun);35:78. https://doi.org/10.47176//mjiri.35.78

\section{Introduction}

Noncommunicable diseases are one of the primary causes of mortality worldwide (1). Around $80 \%$ of the mortality has been reported in low-income or middleincome countries except African countries (2). Harmful behaviors like smoking, alcohol consumption, physical

\section{Corresponding author: Zahra Amiri, stud248000230@sums.ac.ir}

${ }^{1 .}$ Student Research Committee, Shiraz University of Medical Sciences, Shiraz, Iran

2. Noncommunicable Diseases Research Center, Fasa University of Medical Sciences, Fasa, Iran

3. Infectious Diseases Research Center, Kermanshah University of Medical Sciences, Kermanshah, Iran

4. Clinical Research Development Center, Imam Reza Hospital, Kermanshah University of Medical Sciences, Kermanshah, Iran

${ }^{5 .}$ Hormozgan University of Medical Sciences, Hormozgan, Iran inactivity, and inadequate consumption of fruits and vegetables are the 4 risk factors which have a basic role in producing noncommunicable diseases. Although most of the factors related to life styles are flexible, everyone in each layer of a society should be able to opt a healthy life style

$\uparrow$ What is "already known" in this topic:

There is an inverse relationship between unhealthy diet, improper consumption of fruit, vegetables, and fish with socioeconomic conditions. However, inequality in smoking and its relationship with socioeconomic conditions depend on smoking epidemic in each region. This relationship has different patterns.

\section{$\rightarrow$ What this article adds:}

In recent years, the issue of inequality in health and the poor's health has become globally prominent, which has had remarkable outcomes. Understanding the extent and characteristics of inequality in at society is crucial to set goals for change; thus, health care providers need to realize the extent to which their current or planned policies lead to inequality in order to address it. 
(3). The results of many studies show that low social classes are more vulnerable to diseases, disabilities, and early death (4).

In recent years, there has been a global attention towards health and the poor's health (5). Inequality is usually measured according to socioeconomic status, gender, ethnicity, and geographical distribution. In fact, since measuring inequality can result in allocating health budgets and developing interventions, it seems much more important in practice (6). The changes of inequality over time depend on a country's economic, social, and health policies, and while countries advance economically, inequality may increase (7). Therefore, inequality exists in each country, with varying degrees $(8,9)$.

Although health indexes have advanced during recent years, inequalities are still a global challenge (10). As a result, there should be a transparent view of socioeconomic inequalities for noncommunicable diseases. In Iran, very few studies have been conducted to determine socioeconomic inequalities for noncommunicable diseases. Therefore, this study aimed to determine it by applying concentration index.

\section{Methods}

This cross sectional survey was conducted using the database of Fasa cohort study, southern Iran, in 2017 (11). Participants aged 35 to 70 years were invited to participate in the cohort study, were interviewed, and checked by medical tests. Data were collected using a specific schedule, which was reported elsewhere (12). In this study, the following data were used:

a) Chronic diseases, including diabetes, mental disorders, hypertension, chronic headaches, thyroid disorders, chronic lung diseases, breast cancer, oral and vaginal aphthous, infertility, epilepsy, depression, and paramnesia.

b) Information related to economic status of the families included wealth assessment through some information such as kind of house acquisition (personal or leased), the size of the house, number of rooms, having a telephone, washing and dishwashing machines, TV (LCD or LED), refrigerator, vacuum cleaner, personal computer or laptop, accesses to the internet network at home, bathroom and toilet, and car. Also, the prices of these items were calculated.

Descriptive analysis for each of factors in part (a) was applied. To assess wealth status of the families, principal component analysis (PCA) was used. This indicator had a fewer fluctuation compared to assessments that are based on personal incomes or individual's costs. In this method every person was assessed using related information of property status. The calculated asset index was categorized into 5 quintiles and each included one fifth of the participants. The first quintile consisted of the poorest people, while the fifth included the richest.

Economic and social inequality was measured via concentration index method which ranged between -1 to +1 . This index is one of the most common inequality indicators in economics. This allows to measure inequality in the subject of the health via a health variable observance for every quintile. Concentration index as a tool was used to quantify inequality degree related to wealth versus health variable, which originates from a concentration curve. In this curve $\mathrm{X}$ axis reveals association between percentage of studying population ranking with economic and social status or living standards. It starts from the lowest level of economy and goes on to the highest. In the $\mathrm{Y}$ axis association percentage of health variable (chronic diseases in this study) is included. Distributive Analysis Stata Package (DASP) was usied to calculate the CIs and $95 \%$ confidence interval $(95 \% \mathrm{CI})$.

If the health status is equally distributed in every quintile of the society, the concentration curve would be concentrated with diagonal line and form a 45-degree equality line (concentration index is zero). If health is concentrated among deprived levels of the society, concentration curve would be located above the dliagonal line (concentration index is negative). Finally, if the concentration curve is located below the diameter line, inappropriate health status would be concentrated among rich levels of the society (concentration index is positive), and the farther the center curve is from the diagonal line, the greater the inequality.

In this method the dichotomous variable was considered for the asset index. That is the 2 lowest quintiles (Q1 and Q2) were combined and considered as the reference group and the 2 highest ones (Q4 and Q5) were considered for comparison. The noncommunicable diseases were considered as dependent variable and asset index as the independent variable. The OR was reported for each category of the noncommunicable diseases. All statistical analyses were performed by Stata software version 14 (StataCorp).

\section{Results}

Percentage and distribution frequency of each quintile are presented in Table 1. In total, 7990 individuals were included in the study, among whom $983(12.3 \%)$ had diabetes, $1502(18.8 \%)$ recurrent headaches, $83(1 \%)$ tough disorder, 1590 (19.9\%) mouth aphthous, and 284 (3.6\%) genital aphthous. Moreover, 1111 (13.9\%) participants had infertility, $1658(20.8 \%)$ hypertension, $12(0.2 \%)$ breast cancer, 81(1\%) epilepsy, 1325 (16.6\%) chronic headaches, and 525 (6.6\%) depression. Furthermore, paramnesia was confirmed in $74(0.9 \%)$ patients, of whom $856(10.7 \%)$ had learning disability, 149 (1.9\%) chronic lung disease, and $688(8.6 \%)$ thyroid disorders.

Table 2 presents concentration index for evaluated diseases in association with their significance level. The concentration index $(-0.021)$ for the diabetes revealed that disease concentration was observed among those with low socioeconomic level. The results revealed the concentration of epilepsy was significantly more among poor quintiles (concentration index: -0.334). The value of the concentration index for recurrent headaches was -0.03 , indicating that the disease is concentrated in those with lowincome in the society. The concentration index for hypertension, learning disability, paramnesia, chronic headaches and infertility was $0.057,-0.063,-0.225,-0.046$, and 0.028 , respectively. Based on these results, the concentration of the mentioned diseases was significant among the poorest in the society. Breast cancer with a concentration index value of 0.298 indicated the concen- 
Table 1. Percentage and distribution frequency of the chronic diseases in Fasa city, Iran, 2017

\begin{tabular}{|c|c|c|c|c|c|c|c|}
\hline Variables on & & Poorest quintile & $2^{\text {nd }}$ quintile & Middle quintile & 4th quintile & Richest quintile & Total \\
\hline \multirow[t]{2}{*}{ Diabetes } & Yes & $204(2.6 \%)$ & $207(2.6 \%)$ & $185(2.3 \%)$ & $199(2.5 \%)$ & $188(2.4 \%)$ & $983(12.3 \%)$ \\
\hline & No & $17.4(13.94 \%)$ & $1392(17.4 \%)$ & $1412(17.7 \%)$ & $1399(17.5 \%)$ & $1410(17.6)$ & $7007(87.7 \%)$ \\
\hline \multirow[t]{2}{*}{ Recurring Headaches } & yes & $352(4.4 \%)$ & $308(3.9 \%)$ & $288(3.6 \%)$ & $293(3.7 \%)$ & $261(3.3 \%)$ & $1502(18.8 \%)$ \\
\hline & NO & $1246(15.6 \%)$ & $1291(16.2)$ & $1309(16.4 \%)$ & $1305(16.3 \%)$ & $1337(16.7 \%)$ & $6488(81.2 \%)$ \\
\hline \multirow[t]{2}{*}{ Tough disorder } & yes & $23(0.3 \%)$ & $16(0.2 \%)$ & $22(0.3 \%)$ & $10(0.1 \%)$ & $12(0.2 \%)$ & $83(1 \%)$ \\
\hline & NO & $1575(19.7 \%)$ & $1583(19.8 \%)$ & $1575(19.7 \%)$ & $1588(19.9)$ & $1586(19.8)$ & $7907(99 \%)$ \\
\hline \multirow[t]{2}{*}{ Mouth aphthous } & YES & $316(4 \%)$ & $305(3.8 \%)$ & $314(3.9 \%)$ & $338(4.2 \%)$ & $317(4 \%)$ & $1590(19.9 \%)$ \\
\hline & NO & $1282(16 \%)$ & $1294(16.2 \%)$ & $1283(16.1 \%)$ & $1260(15.8 \%)$ & $1281(16 \%)$ & $6400(80.1 \%)$ \\
\hline \multirow[t]{2}{*}{ Genital aphthous } & YES & $58(0.7 \%)$ & $53(0.7 \%)$ & $56(0.7 \%)$ & $62(.08 \%)$ & $55(0.7 \%)$ & $284(3.6 \%)$ \\
\hline & NO & $1540(19.3 \%)$ & $1546(19.3 \%)$ & $1541(19.3 \%)$ & $1536(19.2 \%)$ & $1543(19.3 \%)$ & $7707(96.4 \%)$ \\
\hline \multirow[t]{2}{*}{ Infertility } & YES & $313(3.9 \%)$ & $249(3.1 \%)$ & $203(2.5 \%)$ & $212(2.7 \%)$ & $134(1.7 \%)$ & $1111(13.9 \%)$ \\
\hline & NO & $1285(16.1 \%)$ & $1350(16.9 \%)$ & $1394(17.4 \%)$ & $1386(17.3 \%)$ & $1464(18.3 \%)$ & $6879(86.1 \%)$ \\
\hline \multirow[t]{2}{*}{ Hypertension } & YES & $386(4.8 \%)$ & $351(4.4 \%)$ & $337(4.2 \%)$ & $314(3.9 \%)$ & $270(3.4 \%)$ & $1658(20.8 \%)$ \\
\hline & NO & $1212(15.2 \%)$ & $1228(15.6 \%)$ & $1260(15.8 \%)$ & $1284(16.1 \%)$ & $1328(16.6 \%)$ & $6332(79.2 \%)$ \\
\hline \multirow[t]{2}{*}{ Breast cancer } & YES & $1(0.01 \%)$ & 0 & $2(0.02 \%)$ & $5(0.06 \%)$ & $4(0.05 \%)$ & $12(0.2 \%)$ \\
\hline & NO & $1597(20 \%)$ & $1599(20 \%)$ & $1595(20 \%)$ & $1593(19.9 \%)$ & $1594(19.9 \%)$ & $7978(99.8 \%)$ \\
\hline \multirow[t]{2}{*}{ Epilepsy } & YES & $37(0.5 \%)$ & $14(0.2 \%)$ & $14(0.2 \%)$ & $7(\mathrm{O} .1 \%)$ & $9(0.1 \%)$ & $81(1 \%)$ \\
\hline & NO & $1561(19.5 \%)$ & $1585(19.8 \%)$ & $1583(19.8 \%)$ & $1591(19.6 \%)$ & $1589(19.9 \%)$ & $7909(99 \%)$ \\
\hline \multirow[t]{2}{*}{ Chronic Headaches } & YES & $288(3.6 \%)$ & $278(3.5 \%)$ & $275(3.4 \%)$ & $261(3.3 \%)$ & $223(2.8 \%)$ & $1325(16.6 \%)$ \\
\hline & NO & $1310(16.4 \%)$ & $1321(16.5 \%)$ & $1322(16.5 \%)$ & $1337(16.7 \%)$ & $1375(17.2 \%)$ & $6665(83.4 \%)$ \\
\hline \multirow[t]{3}{*}{ Depression } & YES & $107(1.3 \%)$ & $91(1.1 \%)$ & $104(1.3 \%)$ & $103(1.3 \%)$ & $120(1.5 \%)$ & $525(6.6 \%)$ \\
\hline & NO & $1491(18.7 \%)$ & $1508(18.9 \%)$ & $1493(18.7 \%)$ & $1495(18.7 \%)$ & $1478(18.5 \%)$ & $7465(93.4 \%)$ \\
\hline & YES & $33(0.4 \%)$ & $13(0.2 \%)$ & $7(0.1 \%)$ & $14(0.2 \%)$ & $7(0.1 \%)$ & $74(0.9 \%)$ \\
\hline \multirow[t]{2}{*}{ Paramenesia } & NO & $1565(19.6 \%)$ & $1586(19.8 \%)$ & $1590(19.9 \%)$ & $1584(19.8 \%)$ & $1591(19.9 \%)$ & $7916(99.1 \%)$ \\
\hline & YES & $176(2.2 \%)$ & $203(2.5 \%)$ & $167(2.1 \%)$ & $171(2.1 \%)$ & $139(1.7 \%)$ & $856(10.7 \%)$ \\
\hline \multirow[t]{2}{*}{ Learning Disability } & NO & $1442(17.8 \%)$ & $1396(17.5 \%)$ & $1430(17.9 \%)$ & $1427(17.9 \%)$ & $1459(18.3 \%)$ & $7134(89.3 \%)$ \\
\hline & YES & $43(0.5 \%)$ & $23(0.3 \%)$ & $27(0.3 \%)$ & $35(0.4 \%)$ & $21(0.3 \%)$ & $149(1.9 \%)$ \\
\hline Chronic Lung Disease & NO & $1559(19.5 \%)$ & $1576(19.7 \%)$ & $1570(19.6 \%)$ & $1563(19.6 \%)$ & $1577(19.7 \%)$ & $7841(98.1 \%)$ \\
\hline \multirow[t]{2}{*}{ Thyroid disorders } & YES & $136(1.7 \%)$ & $129(1.6 \%)$ & $134(1.7 \%)$ & $162(2 \%)$ & $127(1.6 \%)$ & $688(8.6 \%)$ \\
\hline & $\mathrm{NO}$ & $1462(18.3 \%)$ & $1470(18.4 \%)$ & $1463(18.3 \%)$ & $1436(18)$ & $1471(18.4 \%)$ & $7302(91.4 \%)$ \\
\hline
\end{tabular}

Table 2. Estimated concentration indexes of chronic disease in Fasa city, Iran, 2016

\begin{tabular}{lcc}
\hline Variable & & Concentration Index (95\% CI) \\
\hline Diabetes & -0.021 & $(-0.03,0.001)$ \\
Thought Disorder & -0.158 & $(-0.280,-0.035)$ \\
Recurring Headaches & -0.03 & $(-0.056,-0.0035)$ \\
Genital Aphthous & -0.004 & $(-0.069,0.060)$ \\
Mouth Aphthous & 0.015 & $(-0.010,0.040)$ \\
Hypertension & -0.057 & $(-0.081,-0.032)$ \\
Epilepsy & -0.334 & $(-0.458,-0.209)$ \\
Depression & 0.004 & $(-0.043,0.051)$ \\
Learning Disability & -0.063 & $(-0.099,-0.028)$ \\
Paramnesia & -0.255 & $(-0.386,-0.123)$ \\
Chronic Headaches & -0.046 & $(-0.074,-0.017)$ \\
Chronic Lung Disease & -0.056 & $(-0.151,0.039)$ \\
Thyroid disorders & 0.011 & $(-0.029,0.052)$ \\
Infertility & -0.028 & $(-0.057,0.00002)$ \\
Breast Cancer & 0.298 & $(0.058,0.538)$ \\
\hline
\end{tabular}

tration of the disease in the wealthy strata of society. The concentration index for thyroid disorders and oral aphthous was 0.011 and 0.015 , respectively, indicating they are more likely to occur among the richest people in the society, but they were not statistically significant. Figure 1 shows 3 different kinds of concentration curves by chronic diseases.

\section{Discussion}

The socioeconomic factors that affect health have been greatly considered in recent years. Evaluating concentration curves and indices is helpful for detecting socioeconomic inequalities by comparing the prevalence of noncommunicable diseases among different socioeconomic conditions $(13,14)$. Some studies have been conducted on the effects of socioeconomic factors on health; however, a few of them have evaluated this for noncommunicable diseases (15-18). In this study the effect of socioeconomic factors on noncommunicable diseases was evaluated in Fasa, southern Iran.

Analyzing CIs for noncommunicable diseases indicated inequality in our study, the most of which was related to epilepsy. Inequality was much more prevalent in people with low socioeconomic status. This inequality was true about paramnesia and learning disabilities as well. Measuring socioeconomic inequallity in mental health on 23,000 families in Tehran in 1997, showed that economic conditions are prominent factors affecting this inequality; and the other factors are education level, residence area and unemployment, respectively. Studies that analyzed 

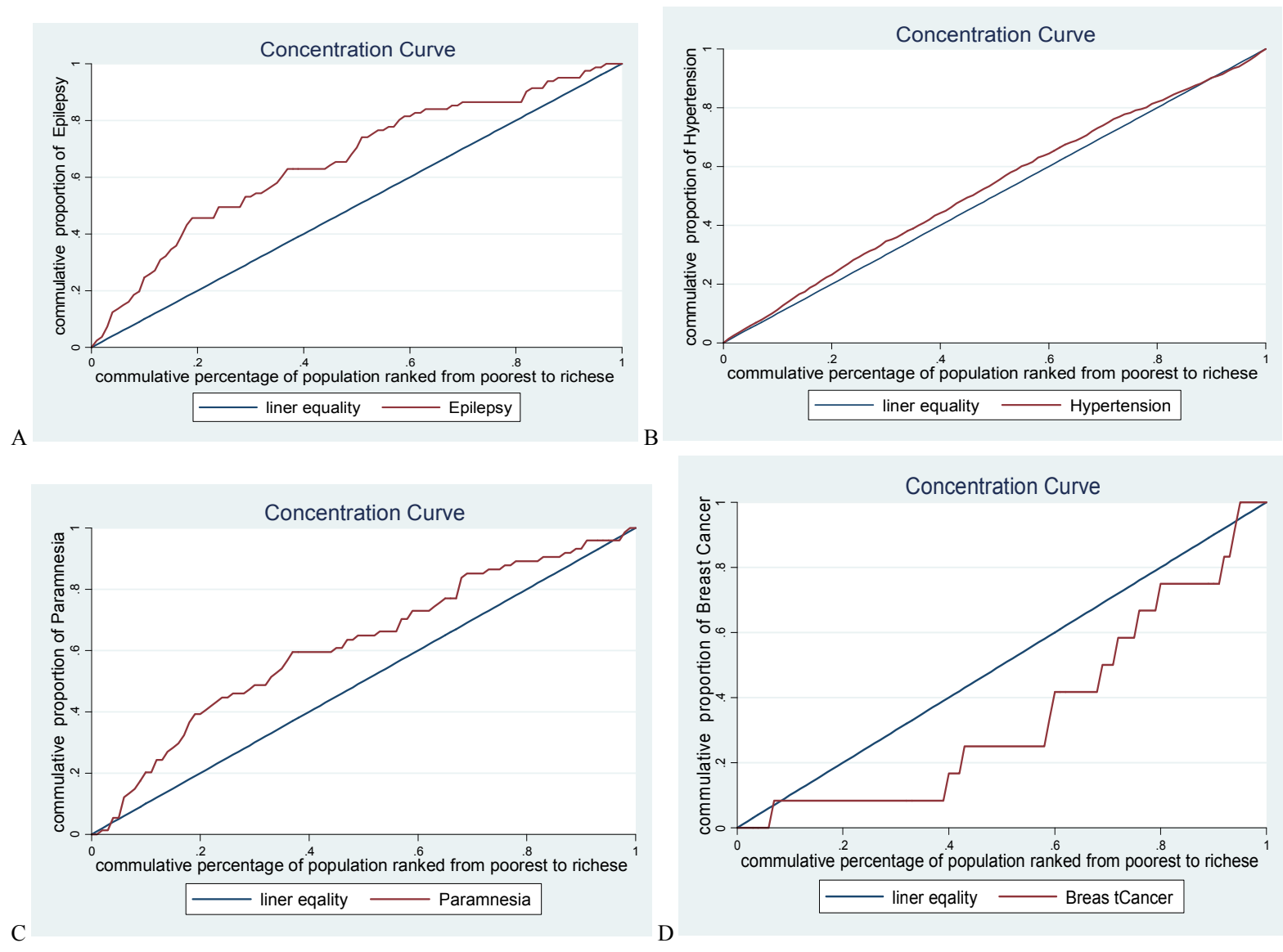

Fig. 1. Different kinds of the concentration curves for A) Epilepsy, B) Hypertension, C) Paramnesia, D) Breast cancer

socioeconomic inequality for mental health have just been limited to developed countries (19). Moreover, the negative amount of CI in the study of Mangalore et al indicates that psychopathy has been distributed improperly between people with lower socioeconomic status (20). According to the results of Wilkinson et al, social inequality is the most prominent cause for psychopathy (21). Hence, without enough attention to social determinants of health, mental health cannot be improved properly (22).

The negative amount of CI in chronic headaches, recurrent headaches, sterility, and stillbirth showed that the higher concentration of these diseases is among poorest people. According to the results of some studies, smoking is a cause of reduced fertility for men and women $(23,24)$. Moreover, according to the study of Vallejo - Terres, smoking occurs more in people with low socioeconomic status (25). The results of our study on inequality in hypertension are consistent with those of many other studies. Many studies have shown an inverse relationship between high blood pressure and socioeconomic status. Such conditions are widely reported in developed countries and countries with high per capita incomes $(26,27)$. However, the results of Spruill et al's study contradict these findings (28). In a study performed on the national data of systolic blood pressure in 2005, a reverse relationship was found between economic status and systolic blood pressure (26). In another study, the focus indices for hypertension in
2005 and 2009 were 0.095 and 0.08 , respectively, indicating that inequality and prevalence of this disease were higher among groups with poor socioeconomic status (27).

In the study of Emamian et al, the greatest inequality after smoking was related to high blood pressure, so that the disease was more prevalent in the group with low socioeconomic status and this group was more affected by this risk factor (28).

A study in the UK found that income-related inequality in health exists in the country, so that despite the declining prevalence of smoking, due to increased concentration among the poor and its negative impact on health, the share of smoking in this inequality has increased.

(25). The study of Yiengprugsawan et al showed that the concentration of noncommunicable diseases is found in those with low socioeconomic status (29). People of low socioeconomic status cannot have easy access to health care for diagnosis and treatment of noncommunicable diseases. Therefore, inequality in noncommunicable diseases is a great obstacle for decreasing the burden of these diseases and accessing to health for all the people (18).

In this study, CI is meaningful for breast cancer, so that each individual of high socioeconomic status may be more afflicted by this risk factor. People with high socioeconomic status consume unhealthy and high-calorie foods 
which is a risk factor for breast cancer, according to Tirona et al's study (30). Moreover, the results of this study show that CI is not meaningful for diabetes, thyroid disorders, depression, and chronic lung diseases. The results of the present study on inequality in diabetes were consistent with those of Emamian et al (28).

The strength of this study was adequate sample size and evaluating several noncommunicable diseases. However, the cross-sectional nature of this study was its limitation. Therefore, what was said as inequality in noncommunicable diseases refers only to the relationship between the studied variables, and there is no causal relationship between them. Thus, using this method is recommended to investigate inequality in longitudinal studies with appropriate design.

\section{Conclusion}

Noncommunicable diseases have been accompanied by inequality in different socioeconomic status of Fasa, so that people with lower socioeconomic status were more afflicted by epilepsy, paramnesia, learning disabilities, chronic headaches, recurrent headaches, sterility, stillbirth, and hypertension. Moreover, breast cancer was more prevalent in those with higher socioeconomic status. These inequalities should be considered more by policymakers to decrease the burden of noncommunicable diseases by recognizing vulnerable subcategories.

\section{Acknowledgment}

The authors would like to thank all staff working in the Fasa NCDs cohort study. The authors declare that there is no conflict of interest.

\section{Conflict of Interests}

The authors declare that they have no competing interests.

\section{References}

1. Mendis S, Davis S, Norrving B. Organizational Update. Stroke. 2015;46(5):e121-e2.

2. Forouzanfar MH, Alexander L, Anderson HR, Bachman VF, Biryukov $\mathrm{S}$, Brauer $\mathrm{M}$, et al. Global, regional, and national comparative risk assessment of 79 behavioural, environmental and occupational, and metabolic risks or clusters of risks in 188 countries, 1990-2013: a systematic analysis for the Global Burden of Disease Study 2013. Lancet. 2015;386(10010):2287-323.

3. Hosseinpoor AR, Bergen N, Kunst A, Harper S, Guthold R, Rekve D, et al. Socioeconomic inequalities in risk factors for non communicable diseases in low-income and middle-income countries: results from the World Health Survey. BMC Public Health. 2012;12(1):912.

4. Hattersley L. Expectation of life by social class. Health Inequalities Office for National Statistics (Series DS No 15), TSO: London. 1997.

5. Marmot M. Achieving health equity: from root causes to fair outcomes. Lancet. 2007;370(9593):1153-63.

6. Cockerham WC. Health lifestyle theory and the convergence of agency and structure. J Health Soc Behav. 2005 Mar;46(1):51-67.

7. Hosseinpoor AR, Van Doorslaer E, Speybroeck N, Naghavi M, Mohammad K, Majdzadeh R, et al. Decomposing socioeconomic inequality in infant mortality in Iran. Int $\mathrm{J}$ Epidemiol. 2006;35(5):1211-9.

8. Hosseinpoor AR, Parker LA, d'Espaignet ET, Chatterji S. Socioeconomic inequality in smoking in low-income and middleincome countries: results from the World Health Survey. PloS One. 2012;7(8):e42843

9. Mackenbach JP, Stirbu I, Roskam AJR, Schaap MM, Menvielle G,
Leinsalu M, et al. Socioeconomic inequalities in health in 22 European countries. N Eng J Med. 2008;358(23):2468-81.

10. Judge $\mathrm{K}$, Platt $\mathrm{S}$, Costongs $\mathrm{C}$, Jurczak $\mathrm{K}$. Health inequalities: a challenge for Europe. An independent, expert report commissioned by the UK Presidency of the EU, London. 2006.

11. Poustchi H, Eghtesad S, Kamangar F, Etemadi A, Keshtkar AA, Hekmatdoost A, et al. Prospective Epidemiological Research Studies in IrAN (The PERSIAN Cohort): Rationale, Objectives and Design. Am J Epidemiol. 2017 Nov 14.

12. Farjam M, Bahrami H, Bahramali E, Jamshidi J, Askari A, Zakeri H, et al. A cohort study protocol to amalyze the predisposing factors to common chronic non-communicable diseases in rural areas: Fasa Cohort Study. BMC Public Health. 2016;16(1):1090.

13. Kien VD, Van Minh H, Giang KB, Dao A, Weinehall L, Eriksson M, et al. Socioeconomic inequalities in self-reported chronic noncommunicable diseases in urban Hanoi, Vietnam. Glob Public Health. 2017;12(12):1522-37.

14. Wagstaff A, O'Donnell O, Van Doorslaer E, Lindelow M. Analyzing health equity using household survey data: a guide to techniques and their implementation: World Bank Publications; 2007.

15. Vellakkal S, Subramanian S, Millett C, Basu S, Stuckler D, Ebrahim S. Socioeconomic inequalities in non-communicable diseases prevalence in India: disparities between self-reported diagnoses and standardized measures. PloS One. 2013;8(7):e68219.

16. Van Minh H, Byass P, Chuc NTK, Wall S. Gender differences in prevalence and socioeconomic determinants of hypertension: findings from the WHO STEPs survey in a rural community of Vietnam. J Hum Hypertens. 2006;20(2):109-15.

17. Kien VD, Van Minh H, Giang KB, Weinehall L, Ng N. Horizontal inequity in public health care service utilization for non-communicable diseases in urban Vietnam. Glob Health Act. 2014;7(1):24919.

18. Di Cesare M, Khang YH, Asaria P, Blakely T, Cowan MJ, Farzadfar $\mathrm{F}$, et al. Inequalities in non-communicable diseases and effective responses. Lancet. 2013;381(9866):585-97.

19. Morasae EK, Forouzan AS, Majdzadeh R, Asadi-Lari M, Noorbala AA, Hosseinpoor AR. Understanding determinants of socioeconomic inequality in mental health in Iran's capital, Tehran: a concentration index decomposition approach. Int J Equit Health. 2012;11(1):18.

20. Mangalore R, Knapp M, Jenkins R. Income-related inequality in mental health in Britain: the concentration index approach. Psychol Med. 2007;37(7):1037-45.

21. Cox M, Boyle PJ, Davey PG, Feng Z, Morris AD. Locality deprivation and Type 2 diabetes incidence: a local test of relative inequalities. Soc Sci Med. 2007;65(9):1953-64.

22. Mohit A. A brief overview of the development of mental health in Iran, present challenges and the road ahead. Iran J Psychiatry Behav Sci. 2009;3(2):1-3.

23. Krausz C. Male infertility: pathogenesis and clinical diagnosis. Best Pract Res Clin Endocrinol Metab. 2011;25(2):271-85.

24. Speroff L, Fritz MA. Clinical gynecologic endocrinology and infertility: lippincott Williams \& wilkins; 2005.

25. Vallejo-Torres L, Morris S. The contribution of smoking and obesity to income-related inequalities in health in England. Soc Sci Med. 2010;71(6):1189-98

26. Farzadfar F, Danaei G, Namdaritabar H, Rajaratnam JK, Marcus JR, Khosravi A, et al. National and subnational mortality effects of metabolic risk factors and smoking in Iran: a comparative risk assessment. Popul Health Metr. 2011;9(1):55.

27. Moradi G, Mohammad K, Majdzadeh R, Ardakani HM, Naieni KH. Socioeconomic inequality of non-communicable risk factors among people living in Kurdistan Province, Islamic Republic of Iran. Int J Prev Med. 2013;4(6):671

28. Emamian M, Alami A, Fateh M. Socioeconomic inequality in noncommunicable disease risk factors in Shahroud, Iran. Iran J Epidemiol. 2011;7(3):44-51.

29. Yiengprugsawan V, Lim LL, Carmichael GA, Sidorenko A, Sleigh AC. Measuring and decomposing inequity in self-reported morbidity and self-assessed health in Thailand. Int J Equit Health. 2007;6(1):23.

30. Tirona MT, Sehgal R, Ballester O. Prevention of breast cancer (part I): epidemiology, risk factors, and risk assessment tools. Cancer Invest. 2010;28(7):743-50 